\title{
Fingerprint As A Means of Identification In The Crime Of Murder (Study At Polresta Pematang Siantar)
}

\section{Putri Sari Tampubolon}

North Sumatera University Faculty Of Law. E-mail: putrisari@gmail.com

\section{ARTICLE INFO}

Keywords:

Fingerprint, Time Working

Agreements

Article history:

Received Jan 01, 2020;

Revised Feb 03, 2020;

Accepted Mar 13, 2020;

Online Apr 30, 2020.

\begin{abstract}
The crime of murder is currently one of the most complicated and very serious problems faced by individuals, society, law enforcement, and the government. The impact of this act of killing was felt very strongly by the community, namely the disruption of security and order in society. Therefore, this crime of murder needs to be handled or tackled seriously. It is in this part of the investigation that the Police can take the first step, namely managing the crime scene (TKP) by identifying any evidence found such as objects that are strongly suspected of being related to the incident, including the victim, objects around the victim or in the vicinity of the victim. around the crime scene. And for the purposes of investigation, the Police are authorized or entitled to take several actions that have been regulated or determined by the Law on the Indonesian National Police No. 2 of 2002 in Article 15 paragraph (1), including taking fingerprints and other identities and taking pictures of someone. This is the reason behind the author's interest in writing a thesis with problems including: How is the process of formulating fingerprints (dactyloscopy) in identifying a crime of murder; What is the role of fingerprints as a means of identification in a murder crime and what are the obstacles faced in the process of identifying a murder crime by using fingerprints as a means of identification. The research used in this thesis is a normative juridical research method which in research the author generally uses library materials or secondary data as basic data materials in research activities. Through this thesis, it is hoped that it can provide input for law enforcement officers, especially the POLRI in uncovering the crime of murder through fingerprints as a means of identification. Regarding the realization of the recognition and protection of one's right to life, this is a very serious matter because, as stated earlier, this right is the most essential right for every human being. However, recently, more and more problems have been faced with regard to the realization of this right to life, among which the most common is the deprivation of the right to life. Deprivation of the right to life that we usually or often encounter is by coercion and violence which is generally known in our society as an act of murder or a crime of murder. However, recently, more and more problems have been faced with regard to the realization of this right to life, among which the most common is the deprivation of the right to life. Deprivation of the right to life that we usually or often encounter is by coercion and violence which is generally known in our society as an act of murder or a crime of murder. However, recently, more and more problems have been faced with regard to the realization of this right to life, among which the most common is the deprivation of the right to life. Deprivation of the right to life that we usually or often encounter is by coercion and violence which is generally known in our society as an act of murder or a crime of murder.
\end{abstract}

This is an open access article under the CC BY-NC license. 


\section{Introduction}

Human rights in principle are a set of rights that are inherent in the nature and existence of humans as creatures of God Almighty and are His gift that must be respected, upheld by the State, law, government and everyone for the sake of honor and protection of human dignity.

The crime of murder is currently one of the most complicated and very serious problems faced by individuals, society, law enforcement, and the government, in which the forms or types of methods used in committing the crime of murder are very diverse. As we can see from the mass media, examples of the forms or methods used in committing this type of crime are as follows; mutilation, a criminal act of terrorism which is an act that threatens the safety of the lives of many people and even deprives the right of life of those who are victims, or kills preceded by violence (persecution).

The impact of this act of murder is very strongly felt by the community, namely the disruption of security and order within the community itself, so that this is one of the important reasons human rights and obligations as citizens cannot run in balance as they should. Therefore, this crime of murder needs to be handled or tackled seriously. Which in handling or tackling it is closely related to the role of all levels of society together with the government and law enforcement authorities in this case especially the Indonesian National Police as their role as investigators and investigators as determined by law.

The police themselves to uncover the occurrence of a crime of murder is not an easy thing, the initial procedure carried out by the police is an investigation to find and find an incident that is suspected of being a murder crime, to then determine whether or not further action can be taken, namely an investigation. It is in this part of the investigation that the Police can take the first step, namely managing the crime scene (TKP) by identifying any evidence found such as objects that are strongly suspected of being related to the incident, including the victim, objects around the victim or in the vicinity of the victim. around the crime scene. And for the purposes of investigation, the Police are authorized or entitled to take several actions that have been regulated or determined by the Law on the Indonesian National Police No. 2 of 2002 in Article 15 paragraph (1), including taking fingerprints and other identities and taking pictures of someone.

Taking fingerprints by the police or investigators is considered as one of the efforts or ways that should not be missed to be carried out, where fingerprinting can be carried out on the victim's body, objects attached to the victim's body, objects around the victim, or other objects. Other objects in the vicinity of the incident which are suspected to be related to the occurrence of the crime of murder.

So in other words, taking fingerprints by the investigator is one of the most important actions based on the reason that the fingerprints of every human being are different from one human to another. Then after obtaining the fingerprint, the investigator can use it as a means of identification in a murder crime. By properly and accurately processing these fingerprints as a means of identifying the crime of murder, it is hoped that it can provide a bright spot in revealing who is the perpetrator of the murder, so that material truth can be obtained regarding what happened related to the murder act.

In addition to the police, the government itself in its efforts or forms of responsibility for handling the crime of murder has also made special regulations and certain agencies, such as the Prosecutor's Office and Medicine (psychological or forensic) which later if a murder crime case occurs So in other words, taking fingerprints by the investigators is one of the most important actions based on the reason that the fingerprints of every human being are different from one human to another. other. Then after obtaining the fingerprint, the investigator can use 
it as a means of identification in a murder crime. By properly and accurately processing the fingerprints as a means of identification and then determining whether or not further action can be taken, namely investigation. It is in this part of the investigation that the Police can take the first step, namely managing the crime scene (TKP) by identifying any evidence found such as objects that are strongly suspected of being related to the incident, including the victim, objects around the victim or in the vicinity of the victim. around the crime scene. And for the purposes of investigation, the Police are authorized or entitled to take several actions that have been regulated or determined by the Law on the Indonesian National Police No. 2 of 2002 in Article 15 paragraph (1), including taking fingerprints and other identities and taking pictures of someone.

Taking fingerprints by the police or investigators is considered as one of the efforts or ways that should not be missed to be carried out, where fingerprinting can be carried out on the victim's body, objects attached to the victim's body, objects around the victim, or other objects. Other objects in the vicinity of the incident which are suspected to be related to the occurrence of the crime of murder. So in other words, taking fingerprints by the investigator is one of the most important actions based on the reason that the fingerprints of every human being are different from one human to another. Then after obtaining the fingerprint, the investigator can use it as a means of identification in a murder crime. By properly and accurately processing these fingerprints as a means of identification .

\section{Method}

The research used in this thesis is a normative juridical research method in which the author's research generally uses library materials or secondary data as basic data in research activities. Method of collecting data In writing this thesis used data collection methods as follows: Library Research, namely, Primary legal materials such as; the Criminal Code (KUHP), the Indonesian Police Act; secondary legal materials such as; official government documents in the form of court decisions. Tertiary legal materials or supporting legal materials which include materials that provide instructions and explanations of primary and secondary law as well as primary, secondary, tertiary materials outside the field of law; Field Research (Field Research) That is by conducting research directly into the field. In this case the author directly conducts research at the Identification Center.

BARESKRIM Pematang Siantar Police and conducted an interview with Brigadier M. Nasib (a member of the Identification Center of BARESKRIM Pematang Siantar Police).

Data analysis In this paper, the data analysis used is qualitative, in which the secondary data and primary data obtained are then analyzed qualitatively to be able to answer the problems in this thesis.

\section{Analysis and Results.}

\subsection{The Role Of Fingerprints In The Process Of The Identification Of The Crime Of Murder And Obstacles That Faced In Utilizing}

a. Facilities or Elements Affecting the Role of Fingerprints in the Identification Process. In the use of the fingerprint system as a means of identification, of course there are elements that affect the role of the fingerprint. Among them are the quality of human resources; supporting/auxiliary equipment; and technology systems.

1) Human Resources

Given how important the role of fingerprints in an effort to reveal a crime and catch the perpetrators. So knowledge about fingerprints for every Polri investigator from subordinates to superiors is actually a must that must be possessed, because the 
evidence is overwhelming that the largest percentage of criminals or criminals can be caught because of fingerprint proof. Fingerprints alongside other human traits are powerful tools for searching and finding criminals. So be careful with every fingerprint found at the crime scene (TKP). Furthermore, it is known that the job of taking fingerprints is not an easy job, but a job that requires perseverance, foresight and patience. So to maximize the function or role of fingerprints in the identification process, it must be carried out professionally by officers who are certainly experts in the field of dactyloscopy (fingerprints). Because if the retrieval or development of fingerprints is carried out unprofessionally, the fingerprint data in the computer database of the Criminal Investigation Unit of the National Police will be useless or of no benefit at all. And these investigators who specialize in the field of dactyloscopy should be evenly distributed throughout the police resorts. ${ }^{57}$

2) Support/auxiliary equipment

The availability of equipment and materials needed for officers who take and develop fingerprints found at crime scenes is also very supportive in carrying out the process of identifying a crime. These tools can assist officers in taking latent fingerprints that are found or found in different places or circumstances which may cause difficulties or obstacles in processing (development). Regarding the equipment used as a support or assistant in fingerprint processing, among others, as described in the description in the previous chapter.

3) Technology system

However, no matter how sophisticated the equipment used, the usefulness and success of the role of fingerprints in the identification process also requires a sophisticated technological system and keeps up with the times. So that the use of technological systems that are in line with the times and advances in electronic and information technology, in particular the field of fingerprints (dactyloscopy) plays a very important role in the system of increasing national resilience and security from being undermined by criminals who can endanger economic, political, and even cultural resilience. nation. One of these technology systems is; computer software AFR (Automatic Fingerprint Recognition System) and CAAFIS (Computer Aided Automatic Fingerprint Identification System) which is a place to store or database of fingerprint data obtained. ${ }^{58}$ Again, that in order to use or utilize a sophisticated technological system, the main thing that must be considered is the availability of operator personnel who have knowledge of the system and are skilled at using it.

b. The Role of Fingerprints as a Means of Identification of the Crime of Murder. As stated earlier that at the crime scene (TKP) it is certain that there are fingerprints or other traces, as well as at the location / scene of the murder case. This is based on the idea that to commit a crime such as a murder crime, the perpetrator takes several actions that are likely to come into contact with objects around the crime scene (TKP), so fingerprints are likely to be left on these objects. except, the perpetrator uses hand pads (paper, cloth or gloves).

And based on the results of the study revealed the secret of fingerprints, namely, there have never been two people who have the same and permanent fingerprints. Starting from the results of this study, people use fingerprints to reveal a crime and try to find the culprit.

Knowledge of fingerprints for every Polri investigator from subordinates to superiors, is actually a must that must be possessed, because the evidence is overwhelming that the largest percentage of criminals or criminals can be caught because of fingerprint proof. Fingerprints alongside other human traits are powerful tools to search for and locate criminals. So be careful with any fingerprints found at the crime scene (TKP), because these fingerprints or fingerprints can be collected and then matched with the fingerprints of criminals who 
already stored in the National Police data base called the Computer Aided Automatic Fingerprint Identification System (CAAFIS) located at the National Police Criminal Investigation Unit Identification Center in Jakarta.

And to systematize and streamline the use of fingerprints in the Police itself, a task force has been formed that specifically handles fingerprint issues and fingerprint examinations at the National Police Headquarters (Police Headquarters) laboratory are handled by fingerprint experts. In general, the benefits of this fingerprint function are:

1) As information material in the investigation process, which is the AK-23 fingerprint blank that can be used to take/record 10 fingerprints, and contains complete individual data which includes characteristics, general, special/signals, photos and signatures . This is used to complete information in an effort to trace the history of the perpetrator of the crime/murder crime.

2) As evidence, because fingerprints are one of the material evidences, which never change and are not the same for everyone, so this fingerprint is very effective, efficient and accurate. More broadly, the fingerprint system has a dual role in the investigation of criminal cases, especially cases of murder, namely:

a) As an effort to trace the criminal history of the arrested murder suspects and as documentation of the criminals who were sentenced by the court.

b) As an effort to track down the perpetrators of crime, especially the crime of murder whose identity is not / not yet known, but accidentally and without realizing it, leaves fingerprints (latent fingerprints) at the crime scene (TKP). In order for this fingerprint system to play a role / function in the process of investigating or identifying a crime, especially a crime of murder, it must be supported by several things as described in detail in the previous description, which are briefly as follows:

c) Adequate and even distribution of specialist investigators/experts in the field of fingerprints (dactyloscopy) throughout the Police Resort (POLRES).

d) There are trained fingerprint takers.

e) Availability of equipment and materials needed for fingerprint takers and development officers.

f) There are methods of retrieval, processing and analysis that have been mastered by the officers concerned.

g) Mastery of modern technology systems, centered on information systems.

The use of the fingerprint system in identifying a crime or crime such as murder is still rare in Indonesia. However, even so in a murder where the perpetrator may be wearing a mask or the perpetrator of the murder has never been identified as the perpetrator of the crime, then with the help of this fingerprint system the perpetrators can finally be caught and brought to justice and the fingerprints that have been developed or processed can function as evidence in the evidentiary process.

\subsection{Constraints in the Identification Process Using Fingerprints as a Means of Identification.}

Based on the research results obtained from the Pematang Siantar Police, namely with Mr. Brigadier M. Nasib at the BARESKRIM Identification Center of the Pematang Siantar Police, it is generally known that the obstacles faced in the utilization or use of the fingerprint system in the identification process, which include:

a. Human resources, meaning that the number of personnel or self-identification officers who master or are experts in the field of fingerprint identification is still inadequate.

b. The incompleteness of supporting/auxiliary equipment in fingerprint identification as well as facilities and infrastructure which are also not evenly distributed among each Police Resort. The use of technology systems that are centered on information systems is still very limited, due to the lack of mastery of technology systems by the identification officers themselves. Thus causing the application of fingerprint processing quickly and accurately is also limited. 


\subsection{Sample case.}

The use of fingerprints as a means of identification in the crime of murder is not often found in Indonesia, but there are several, for example:

The criminal case of murder with the defendant named Harri Hutabarat has been charged with the crime of murdering the victim named $\mathrm{Ng}$ Teng So alias Samsudin with a summary of the incident/case as follows:

On Monday, July 21, 2008 at around $06.30 \mathrm{WIB}$, the complainant named $\mathrm{Ng}$ Teng $\mathrm{Yu}$ alias Berkat as the owner of the Andalas shop Jl. Merdeka intersection Jl. Bandung No. 104 Ex. Dwikora district. West Siantar Pematang Siantar city. When the reporter, Ng Teng Yu alias Berkat was about to open the door of the shop, he saw that the side of the shop was filled with crowds of people, and when the reporter approached the crowd, he found a lying man who he knew named $\mathrm{Ng}$ Teng So alias Samsudin who was none other than his real brother. the complainant himself, and the condition of the person was covered in blood and covered with a sarong, which was suspected to have been killed by an unknown person. Furthermore, the reporter reported the incident to the West Siantar Police, Pematang Siantar City, because the victim Ng Teng So alias Samsudin was allegedly murdered. And on Thursday, July 24, 2008 when officers from the West Siantar Police on patrol saw a man lying on the road in an unconscious state which was later found to be due to an electric shock, then the officers took the man to Djasamen Saragih Hospital, Pematang Siantar City for received treatment, not long after the man regained consciousness and received treatment, the officers interrogated him until it was discovered that his name was Harri Hutabarat, then the officer continued by asking the man what caused him to be electrocuted, and according to his confession because he intends to steal the power cable behind the Horas Market Police Post, West Siantar District, Pematang Siantar City, and alias Samsudin a fruit seller at the intersection of Jl. Merdeka - Jl. Bandung, who is suspected of having been killed, the man initially said he did not know anything about the incident, and later said he did not feel involved in the incident. Then the officers continue to investigate and identify until clues and evidence are collected to be used in an effort to find the suspect who committed the murder, to then be used as a defendant in court and the evidence is sufficient to be faced in the evidentiary process in court.

Then the evidence is processed by officers, one of which is fingerprint identification, which at this stage several things are done as follows: How to carry out fingerprints; researching/developing fingerprints; filing; latent fingerprint investigation; latent fingerprint formulation; fingerprint investigation of corpses/victims; fingerprint investigation of the suspect/perpetrator; make fingerprint photos; expose fingerprints as evidence in the judicial process.

Fingerprint identification is carried out on objects found at the crime scene (TKP) and around the murder scene, which include penknife, dagger, blue mancis and other items, by processing and developing latent fingerprints obtained from these objects go through the stages or processes as described the previous description. And in addition to dactyloscopy identification, signal identification and photographic identification were also carried out.

And based on the results of the investigation and identification as well as conducting interrogations that have been carried out by the Polsek officers against several witnesses, then the investigators have concluded that the suspect in the murder is none other than the suspect against Harri Hutabarat. Previously, interrogation and taking fingerprints as well as signaling data from the person concerned had been carried out. So it was found that the pattern/main shape of the fingerprint painting found at the crime scene with that of Hari Hutabarat's brother was found, which means in other words the investigator or identification officer found the identity between the comparison fingerprint and the latent fingerprint. Likewise, by matching Harri Hutabarat's signaling data obtained through identification of evidence with statements 
from witnesses. So the officers raised Harri Hutabarat's status from a witness to a suspect perpetrator and then a defendant in the judicial process. Fingerprints and other data that have been developed or processed can be used as evidence in the evidentiary process.

So that at the time of the trial, in the evidentiary process several items of evidence as mentioned above, and also the results of processing and developing latent fingerprints were obtained. Which through the results of the examination/comparison or fingerprint identification, the panel of judges consists of: AMSiringoringo, $\mathrm{SH}, \mathrm{MH}$ (Chairman Judge); Dahlia Panjaitan, $\mathrm{SH}$ (Member Judge); J. Simarmata, SH (Member Judge), who is authorized to try this murder case, includes him as evidence which will become one of several considerations of the panel of judges in making or formulating the contents of its decision.

\section{Conclusion}

.In the case of a murder crime, the precise and accurate formulation of fingerprints plays a very important role in the investigation and proof process, with the following stages: searching for fingerprints at the crime scene or around the crime scene; then confirm the location of the fingerprint; taking fingerprints (eg fingerprints from people who were right at the crime scene or around the crime scene); and lastly examination of the comparison (formulation) of fingerprints in the identification process. This last stage is the most important stage because it is carried out to determine whether the two fingerprints have the same painting shape and are identical fingerprints, meaning by seeing whether the flow of papillary lines between the two fingerprints is the same.

To determine two identical or identical fingerprints, there are several factors that must be assessed orseen, among others, are through: a) The basic form of fingerprint painting between latent fingerprints and comparison fingerprints, namely: the two fingerprints being compared must be the same, although their identity cannot be determined, if other factors are not/not fulfilled; b) Characteristics of the fingerprint papillary lines (detailed galtons) the type and shape of the detailed galtons between the two fingerprints (latent fingerprints and comparison fingerprints) must be of the same shape, position, and direction; c) The number of equation points (galton details of the same type, shape, direction and position) then: if the equation points are 11-12 or more, it means that the identity is definite; if the point of the equation is 810, it means that the identity still has to be strengthened with things like; the clarity of fingerprints, the presence of cores or deltas of the principal forms of fingerprint paintings that are rarely found.

In general, the benefits obtained from this fingerprint function are: As information material in the investigation process, which is the AK-23 fingerprint form that can be used to take/record 10 fingerprints, and contains complete individual data which includes characteristics features, general, special / signal, photos and signatures. This is used to complete information in an effort to trace the history of the perpetrators of crimes/criminal acts of homicide; As evidence, because fingerprints are one of the material evidences, which never change and are not the same for everyone, so this fingerprint is very effective, efficient and accurate. More broadly, the fingerprint system has a dual role in the investigation of criminal cases, especially cases of murder, namely: (1) As an effort to trace the criminal history of the arrested murder suspects and as documentation of the criminals sentenced by the court; (2) As an effort to track down the perpetrators of crimes, especially the crime of murder whose identity is not / not yet known, but accidentally and without realizing it, leaves fingerprints (latent fingerprints) at the crime scene (TKP). In general, it is known that the obstacles faced in the utilization or use of the fingerprint system in the identification process, among others: Human resources, meaning that the number of personnel or self-identification officers who master or are experts in the field of fingerprint identification is still inadequate. The incompleteness of supporting/auxiliary equipment in fingerprint identification as well as facilities and infrastructure which are also not 
evenly distributed among each Police Resort. The use of technology systems that are centered on information systems is stillvery limited, due to the lack of mastery of the technology system by the identification officer himself. Thus causing the application of fingerprint processing quickly and accurately is also limited. Difficulties - difficulties also encountered by officers or fingerprint experts in identifying, namely: 1) Two fingerprints will be difficult or may not be identified if they are of different types; 2) Fingerprint marks found at the crime scene (TKP) often show imperfect or blurry shapes because they are scratched, stained, or overlapped with other fingerprints. Although this does not make identification impossible. Comparing fingerprints that have been recorded and those obtained at the crime scene is not a special science, but depends on the expertise and experience of the expert. If it meets the characteristics between the two fingerprints (latent and recorded fingerprints), then identification can be done. Differences in the conclusions of experts occur if the characteristics of fingerprints are obtained to a minimum. So sometimes other experts argue that the data is insufficient for identification;

Another difficulty is that fingerprints should have been recorded in the Police file beforehand. However, the file system in the Police is still not good, and has not been systematically arranged, and there is still a lot of incomplete fingerprint data, meaning that it is not recorded up to ten fingers. then identification can be done. Differences in the conclusions of experts occur if the characteristics of fingerprints are obtained to a minimum. So sometimes other experts argue that the data is insufficient for identification; 3) Another difficulty is that fingerprints should have been recorded in the Police file beforehand. However, the file system in the Police is still not good, and has not been systematically arranged, and there is still a lot of incomplete fingerprint data, meaning that it is not recorded up to ten fingers. then identification can be done. Differences in the conclusions of experts occur if the characteristics of fingerprints are obtained to a minimum. So sometimes other experts argue that the data is insufficient for identification; 3) Another difficulty is that fingerprints should have been recorded in the Police file beforehand. However, the file system in the Police is still not good, and has not been systematically arranged, and there is still a lot of incomplete fingerprint data, meaning that it is not recorded up to ten fingers. fingerprints should have been recorded in the Police file beforehand. However, the file system in the Police is still not good, and has not been systematically arranged, and there is still a lot of incomplete fingerprint data, meaning that it is not recorded up to ten fingers. fingerprints should have been recorded in the Police file beforehand. However, the file system in the Police is still not good, and has not been systematically arranged, and there is still a lot of incomplete fingerprint data, meaning that it is not recorded up to ten fingers.

\section{References}

Abdussalam, HR, Forensic, Restu Agung, 2006.

Aiptu Sihombing, Resume / Police Report No. Pol : LP / 38 / VII / 2008 / West Siantar dated July 21, 2008 (Decision on Criminal Cases with Register No. 330/Pid.B/2008/PN-PMS Pematang Siantar).

Hamzah, Andi, Investigation of Criminal Cases Through Technical and Legal Facilities, GHALIA INDONESIA, 1986.

Andi, Indonesian Criminal Procedure Law, Arikha Media Cipta, Jakarta 1993.

Hamid, H. Hamrat and M. Husein, Harun, Discussion of the Problems of the Criminal Procedure Code in the Field of Investigation, SINAR GRAFIKA, 1997.

Karjadi, M, First Action and Investigation at the Crime Scene, POLITEIA, Bogor, 1981. 
Kelana, Momo, Understanding Police Law, PTIK Press, 2002. Lamintang, PAF, Special Offenses for Crimes Against Life, Body and Health and Crimes That Are Dangerous to Life, Body and Health, Bina Cipta, Bandung, 1985.

Marpaung, Leden, Crime Against Life and Body (Eradication and Prevention), Sinar Graphica, 1999.

M. Husein, Harun, Investigation and Prosecution in the Criminal Process, PT. Rineka Cipta, 1991.

Prakoso, Djoko, Police as Investigators in Law Enforcement, PT. Literature Development, Jakarta 1987.

Pusident Bareskrim Polri, Criminal Dactyloscopy in Support of Scientivic Crime Investigation, POLDASU, 2006.

Saleh, MR. Roeslan, Criminal Acts and Criminal Liability. Two Basic Definitions in Criminal Law, New Aksara, Jakarta, 1983.

Soesilo, R, Tactics and Techniques of Criminal Investigation, POLITEIA, Bogor. Soedjadi, Brigadier General of Police (Director of Police Investigation) and Kafandi, General

Police (Komando Reserse Pori), Association of Juklak and Technical Guidelines on Criminal Investigation Processes, Indonesian National Police Headquarters, 1987.

Suwarto, Irwan, POLRI in the dynamics of the Indonesian state administration, Padang; Ekasakti Press, 2002.

W. Bawengan, Gerson Criminal Investigations and Interrogation Techniques, PT. Pradnya Paramita, Jakarta, 1977.

Yuwono, Soesilo, Settlement of Criminal Cases Based on the Criminal Procedure Code, Alumni Publisher, Bandung, 1982.

Law No. 2 of 2002 About Police Country Republic Indonesia. the Criminal Code (KUHP). The Criminal Procedure Code (KUHAP). www.mabespolri.com. 